\title{
A TRAJETÓRIA DA PÓS-GRADUAÇÃO NO BRASIL E A ANPEGE: ALGUMAS QUESTÕES
}

José Borzacchiello da Silva

Professor do Programa de Pós-Graduação em Geografia da Universidade Federal do Ceará Presidente da Associação Nacional de Pós-Graduação e Pesquisa em Geografia, biênio 2003-2005

borza@secrel.com.br

Márcio Piñon de Oliveira

Professor do Programa de Pós-Graduação em Geografia da Universidade Federal Fluminense Presidente da Associação Nacional de Pós-Graduação e Pesquisa em Geografia, biênio 2005-2007 marpinon@hotmail.com

\section{Resumo}

O artigo aqui proposto procura recuperar a trajetória da pós-graduação no Brasil e relacioná-la com o desenvolvimento acadêmico e científico da geografia brasileira e o surgimento da Associação Nacional de Pós-Graduação e Pesquisa em Geografia (ANPEGE). Como antecedentes importantes à criação da ANPEGE assinalamos três períodos: a) o período que vai de 1931 à fundação da CAPES em 1951, marcado pelo nascimento de importantes universidades e da pós-graduação no Brasil; b) o período delimitado pela fundação da CAPES até 1982, pautado pela forte institucionalização da pós-graduação no país; c) e aquele que se estende de 1982 a 1995, caracterizado, sobretudo, pela implantação do sistema de avaliação e a consolidação institucional da CAPES. A ANPEGE nasceu em 1993, no final desse último período, e início de um novo ciclo, a partir de 1995, marcado por uma expressiva expansão da pós-graduação em todo país nas diferentes áreas do conhecimento, e em particular na geografia. Atualmente, colocam-se novos desafios a serem enfrentados pela entidade, dentre eles os debates acerca do "produtivismo", do "fracasso da formação" e da política de fomentos.

\section{Résumé}

L'article proposé récupère la trajectoire de la post-graduation au Brésil et son rapport avec le développement académique et scientifique de la géographie brésilienne et la creation de l'Association Nationale de de Post-Graduation et Pesquisa dans Géographie (ANPEGE). Comme antécédents importants à la création de ANPEGE nous désignons trois périodes: a) période qui va de 1931 à la fondation de CAPES en 1951, marqué par la naissance des importantes universités et de la post-graduation au Brésil ; b) la période délimitée par la fondation de CAPES jusqu'en 1982, réglée par la forte institutionnalisation de la post-graduation dans le pays; c) et celui qui s'élargit de 1982 à 1995, caractérisé, surtout, par l'implantation du système d'évaluation et la consolidation institutionnelle de CAPES. ANPEGE est née en 1993, à la fin de cette dernière période, et au début d'un nouveau cycle, à partir de 1995, marqué par une expressive expansion de la post-graduation dans tout les pays parmi les différents secteurs de la connaissance, et en particulier dans la géographie. Actuellement, il y a de nouveaux défis à être affrontés par l'entité, parmi eux les débats concernant le " produtivismo », des « échecs de la formation » et des politique de financement.

Mots-Clés: Post-Graduation; Brésil; Géographie; ANPEGE.

Palavras-chave: Pós-Graduação; Brasil; Geografia; ANPEGE.

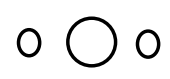

\section{INTRODUÇÃO}

Neste primeiro momento gostaríamos de pontuar, em linhas gerais, a trajetória da pós-graduação no Brasil e as relações com a produção em Geografia, que antecedem a criação da ANPEGE - Associação Nacional de Pós-Graduação e Pesquisa - nos anos 1990, para que possamos situar as especificidades do nosso campo, para em seguida colocarmos para o debate algumas questões no período mais recente.

Antes da origem da ANPEGE assinalamos três momentos importantes na trajetória da pós-graduação brasileira, a destacar:

Revista da ANPEGE. v. 5, 2009 
a) o período que vai de 1931 à fundação da CAPES em 1951;

b) o período marcado pela fundação da CAPES até 1982;

c) e aquele que se estende de 1982 a 1995.

\section{ANTECEDENTES}

\section{Criação de universidades e pós-graduação}

As primeiras medidas legais nesse percurso se deram no Governo Provisório de Getúlio Vargas, no início da década de $1930^{1}$, por iniciativa de Francisco Campos, que na época era Ministro da Educação e Saúde Pública. Por meio do decreto no 19.851, de abril de 1931, foi instituída no Brasil a "investigação científica em quaisquer domínios dos conhecimentos humanos" (art. $\left.1^{\circ}\right)$ como finalidade do ensino universitário. Segundo Cury (2005, p. 8), "esse decreto institucionaliza também cursos de aperfeiçoamento e de especialização como forma de aprofundamento de conhecimentos profissionais e científicos", assim como estabelece, no seu art. 32, que "nos institutos universitários será atendido a um tempo o duplo objetivo de ministrar o ensino eficiente dos conhecimentos humanos adquiridos e de estimular o espírito de investigação original, indispensável ao progresso das ciências" (Idem).

O decreto também previa um Museu Social (art. 110) como lugar congregador de informação e de pesquisas voltadas para os problemas nacionais. O título de doutor, expresso no art. 90, devia se apoiar em uma tese, do que resultaria tanto a expedição de um diploma quanto à assinalação de uma dignidade honorífica. (Cury, 2005, p.8)

Assim, o decreto $\mathrm{n}^{\circ} 19.851$ conferira as universidades nascentes o duplo atributo de lugares realizadores de pesquisas e, ao mesmo tempo, de lugares formadores de pesquisadores e doutores em ciências. Nesse sentido, esse decreto cola, desde a origem de sua institucionalização, a investigação científica, a saber, a pesquisa, nos seus diferentes domínios, com a finalidade de ensino dos institutos universitários.

É desses anos de 1930 a criação da Universidade de São Paulo (USP) ${ }^{2}$, com a contratação de inúmeros professores/pesquisadores estrangeiros e também do curso de doutorado em direito da Universidade de Minas Gerais, atual UFMG (Cury, 2005, p. 8). O Curso de Geografia da USP é de 1934, com a participação de importantes professores franceses em sua fundação, a exemplo de Pierre Deffontaines e Pierre Monbeig ${ }^{3}$. Nessa mesma conjuntura, e quase que simultâneo ao surgimento do Curso de Geografia da USP, nascem a Associação de Geógrafos Brasileiros (AGB), fundada em 17 de setembro de 1934, em São Paulo, e o IBGE criado em $1937^{4}$. Assinam a Ata de Fundação da AGB: Pierre Deffontaines (presidente), Caio Prado Jr (secretário), Rubens Borba de Moraes (tesoureiro) e Luiz Flores de Moraes Rego 5 . É importante ressaltar que até a criação da ANPEGE em 1994, foi a AGB que no campo profissional representou no cenário nacional a Geografia brasileira, se pronunciando, inclusive, no tocante a assuntos relativos à pós-graduação.

É ainda desse período a criação, em 1949, do Conselho Nacional de Pesquisa, hoje conhecido como CNPq (Conselho Nacional de Desenvolvimento Científico e Tecnológico). Esse conselho, criado por iniciativa do presidente Dutra, foi regulamentado pela lei $\mathrm{n}^{\circ} 1.310 / 51$, e tinha por finalidade, no seu art. $3^{\circ}$ :

a) promover investigações científicas e tecnológicas por iniciativa própria, ou em colaboração com outras instituições no país ou no exterior;

b) auxiliar a formação e o aperfeiçoamento de pesquisadores e técnicos, organizando ou cooperando na organização de cursos especializados, sob a orientação de professores nacionais ou estrangeiros, concedendo bolsas de estudo ou de pesquisa e promovendo estágios em instituições técnico-científicas e em estabelecimentos industriais no país ou no exterior; 
c) manter-se em relação com instituições nacionais ou estrangeiras para intercâmbio de documentação técnico-científica e participação nas reuniões e congressos, promovidos no país ou no exterior para estudo de temas de interesse comum. (apud Cury, 2005, p. 8)

Ainda hoje o CNPq é um dos pilares de sustentação e da promoção da pesquisa e formação de quadros técnico-científicos, nos quais se incluem a pós-graduação, em todas as áreas do conhecimento, por meio de diferentes tipos de bolsas, auxílios e investimentos. Nesse sentido, a sua atuação veio complementar/ reforçar, como órgão de fomento, o desenvolvimento da pesquisa aliada a formação de pesquisadores nas instituições universitárias brasileiras.

\section{A criação da CAPES e os alicerceis da pós-graduação}

Na década de 1950 “a geração de conhecimento e a formação de recursos humanos faziam parte da estratégia de crescimento rápido e acelerado desejado para o país, tendo como elemento propulsor a expansão do setor produtivo" (Barros, 1998, p. 82). Entre 1950 e 1960 havia uma forte corrente que defendia o doutorado como forma regular e institucionalizada de se criar um corpo permanente de cientistas no país (Carvalho, 1992). Em 1952, o governo brasileiro firmou um acordo com os Estados Unidos através do qual se celebraram diversos convênios entre universidades. Desse modo, muitos estudantes foram para os Estados Unidos para fazer mestrado e doutorado e muitos professores norte-americanos vieram para o Brasil a fim de desenvolver programas de pós-graduação (Cury, 2009, p.9). No âmbito da Geografia, foram os geógrafos que trabalhavam no IBGE nesse período aqueles que mais usufruíram desse estímulo de formação de pessoal em nível de pós-graduação através de convênios celebrados com importantes universidades norte-americanas.

É nesse contexto de expansão do setor produtivo na economia e de estímulo à formação técnico-científica no Brasil dos anos 1950 que surge a CAPES em 1951. Inicialmente denominada como Campanha de Aperfeiçoamento do Pessoal de Nível Superior, vinculada, à época, ao Ministério da Educação e Saúde 6 . Na ocasião, eram poucas as universidades brasileiras onde era possível a realização de estudos de pósgraduação. Tal fato ocorria, em parte, devido às universidades existentes, a exemplo da USP, seguirem, o antigo modelo francês de pós-graduação, com base em cátedras, que visava apenas o título de Doutor. Não havia, portanto, o mestrado e o título de Doutor era ostentado por um número muito pequeno de pessoas (Beiguelman, 1997, p. 39).

A CAPES terá como objetivo geral "assegurar a existência de pessoal especializado em quantidade e qualidade suficientes para atender às necessidades dos empreendimentos públicos e privados que visam ao desenvolvimento do país"7.

Era o início do segundo governo Vargas, e a retomada do projeto de construção de uma nação desenvolvida e independente era palavra de ordem. A industrialização pesada e a complexidade da administração pública trouxeram à tona a necessidade urgente de formação de especialistas e pesquisadores nos mais diversos ramos de atividade: de cientistas qualificados em física, matemática e química a técnicos em finanças e pesquisadores sociais. ${ }^{8}$

Nesse sentido, em 1953, foi implantado o Programa Universitário, que logo se tornou a principal linha de atuação da CAPES junto às universidades e institutos de ensino superior. Na época, Anísio Teixeira, seu primeiro presidente, iria contratar inúmeros professores visitantes estrangeiros, estimular atividades de intercâmbio e cooperação entre instituições, conceder bolsas de estudos e apoiar eventos de natureza científica 9 .

É em 1964, na aurora dos duros anos do regime militar, que ocorrera a fusão da CAPES, então Campanha de Aperfeiçoamento do Pessoal de Nível Superior, com a Comissão Supervisora do Plano dos 
Institutos (COSUPI) - voltada para a implantação e o desenvolvimento de um programa de educação tecnológica - e com o Programa de Expansão do Ensino Tecnológico (PROTEC) — que visava promover a graduação de maior número de especialistas e técnicos auxiliares nos diferentes ramos da engenharia e da tecnologia em geral ${ }^{10}$. Dessa fusão, surge a Coordenação de Aperfeiçoamento do Pessoal de Nível Superior, a nova CAPES, "subordinada diretamente ao ministro da Educação e Cultura e orientada por um Conselho Deliberativo que detinha propriamente todo o poder decisório, inexistindo um espaço para atuação do corpo técnico da agência" (Barros, 1998, p. 83-84).

Cria-se, também, em 1964, nessa mesma conjuntura, o Fundo de Desenvolvimento Técnico-Científico (FUNTEC), com recursos do então BNDE (Banco Nacional de Desenvolvimento Econômico). Este fundo marcou profundamente o cenário da pós-graduação no Brasil na década de 1960 no financiamento de programas e projetos, uma vez que o CNPq e CAPES utilizavam primordialmente seus recursos no apoio individual através de bolsas para a pós-graduação nas universidades brasileiras. Doravante, o FUNTEC seria transferido integralmente à FINEP (Financiadora de Estudos e Projetos) ${ }^{11}$ que reorientou, para $o$ período pós-1974, os seus objetivos, concentrando os recursos em pesquisa e desenvolvimento (Souza Paula et alii, 1988, p.80-82).

Em 1965, tem-se, no plano educacional, além das reformas universitária e do ensino fundamental, a consolidação do regulamento da pós-graduação através do Parecer CFE $\mathrm{n}^{\circ}$ 977/65 ${ }^{12}$, ganhando a CAPES, assim, novas atribuições e meios orçamentários. Na regulamentação da pós-graduação no país, o Parecer 977/65 destaca, além da origem da pós-graduação, sua definição e caracterização, o estabelecimento de conceitos aos cursos a serem fixados pelo Conselho Federal de Educação - CFE (Cury, 2005, p.11). Isto é importante, pois, é a primeira vez que a palavra conceito aparece na legislação sobre a pós-graduação.

Cresce, nesses anos de 1960, mesmo após a saída de Anísio Teixeira face à ascensão do governo militar, o estímulo à expansão da pós-graduação, com a também criação do Conselho de Ensino Superior ${ }^{13}$ e a ênfase que teria a pós-graduação na polêmica Reforma Universitária de 1968.

É nesse contexto que nasceriam os cursos de pós-graduação na USP, a partir de1969, inclusive o de Geografia, que no ano de 1971 seria desdobrado em dois programas de pós-graduação: Geografia Física e Geografia Humana, ambos com cursos de Mestrado e Doutorado ${ }^{14}$. No ano seguinte, em 1972, seria a vez do programa de Geografia da Universidade Federal do Rio de Janeiro (UFRJ) iniciar o seu curso de mestrado. Esses foram os primeiros programas na área de Geografia no Brasil, formando a nossa primeira geração de mestres e doutores.

No ano de 1970 houve um significativo fortalecimento da CAPES que passa a "órgão autônomo do MEC, em articulação com o Departamento de Assuntos Universitários (DAU/MEC) e com o CNPq. Para assegurar a autonomia financeira da agência é instituído o Fundo de Aperfeiçoamento de Pessoal de Nível Superior" (Barros, 1998, p.84). Além disso, cria-se nesse mesmo ano os Centros Regionais de Pós-Graduação ${ }^{15}$.

Mudança mais significativa, ainda, viria no ano de 1974, através do Decreto 74.29916 , que promoveria uma reforma na estrutura administrativa da CAPES. Com base nesse decreto, o antigo Conselho Deliberativo deixa de existir e no seu lugar passa a funcionar o Conselho Técnico-Administrativo - CTA, que teria a finalidade, na época, propor as grandes linhas de atuação da CAPES em consonância com as diretrizes do Plano Nacional de Desenvolvimento da Pós-Graduação - PNPG, o qual vinha sendo elaborado no âmbito do Conselho Nacional de Pós-Graduação - CNPG; este último criado em 1973 com a responsabilidade de formular a política nacional de pós-graduação.

Uma das razões do fortalecimento da CAPES decorre de sua colaboração com o DAU/MEC na elaboração e implementação do I PNPG. No contexto da institucionalização da pesquisa e da pós-graduação

Revista da ANPEGE v. 5, 2009 
no país o I PNPG incentivou a criação das Pró-Reitorias de Pós-Graduação e Pesquisa, financiadas pelo DAU/MEC e pela CAPES, induzindo o surgimento de novos cursos e possibilitando o controle e a centralização dos recursos através da assinatura de convênios com as agências de financiamento. "As pró-reitorias inauguraram, portanto, uma nova instância de poder. Os projetos e recursos que, na fase inicial da pós-graduação, eram discutidos individualmente com coordenadores/pesquisadores, assumem caráter institucional pela intervenção desse novo agente" Barros (1998, p. 93-94)

Na década de 1970, então, com todo esse estímulo, a pós-graduação se ampliaria significativamente em todas as áreas. Na Geografia, foram criados ainda nessa década, os Programas de Pós-Graduação da Universidade Federal de Pernambuco (UFPE), em 1976, e o da Universidade Estadual Paulista (UNESP/ RC), em Rio Claro, no ano de 1977; ambos com o Curso de Mestrado. É dessa década também o surgimento das primeiras Associações Científicas de Pós-Graduação voltadas para os interesses específicos de suas respectivas áreas. Dentre elas, encontram-se a pioneira ANPEC (Economia), a ANPOCS (Política e Ciências Sociais), ANPAD (Administração). Segundo Córdova et alii (1986, p. 53) essas associações terão em comum "o papel de espaço de intercâmbio acadêmico independente dos quadros institucionais, que lhes permite, ademais, encaminhar suas opiniões e posicionamentos ante as políticas governamentais, específicas de suas áreas de estudo ou de caráter mais geral". Em outras palavras, funcionam como "uma espécie de posto avançado gerador de debate mais livre das amarras institucionais, trazendo algum tipo de repercussão para o contexto que se inserem" (Idem, p. 54).

De acordo com Barros (1998, p.133), os fatores que contribuíram para o fenômeno expansionista da pós-graduação, a partir de meados da década de 1970, foram: a exigência de titulação pós-graduada para a progressão na carreira do magistério superior; a necessidade de formação de pesquisadores para a ciência nacional (em especial para os grandes projetos de desenvolvimento do país); prestígio dos cursos de mestrado e doutorado para as universidades (status e recursos financeiros); pressão dos novos mestres e doutores que, em suas instituições de origem, desejam fomentar um ambiente favorável às atividades docentes e de pesquisa; o próprio I PNPG (Plano Nacional de Desenvolvimento da Pós-Graduação), ao fixar metas para a titulação de novos mestres e doutores.

\section{c) A implantação do sistema de avaliação}

A partir de 1982 uma nova fase será experimentada pela pós-graduação brasileira, que, ao nosso ver, só veio reforçar, como desdobramentos, a forte institucionalização ocorrida na década de 1970 e consolidar o papel da CAPES. Dentre os instrumentos que fortaleceram e consolidaram a ação da CAPES como órgão reitor da pós-graduação no Brasil está o decreto n ${ }^{\circ} 86.816$, de 05/01/198217, que estabeleceu como algumas funções da CAPES:

II- elaborar o Plano Nacional de Pós-Graduação bem como acompanhar e coordenar a sua execução; [...]

I- acompanhar e avaliar os cursos de pós-graduação e a interação entre ensino e pesquisa; [...]

VIII- manter intercâmbio e contato com outros órgãos da administração pública ou com entidades privadas, inclusive internacionais e estrangeiras, visando à celebração de convênios, acordos, contratos e ajustes relativos à pós-graduação e aperfeiçoamento de pessoal de nível superior, obedecidas pela Secretaria Geral do MEC, relativas aos assuntos internacionais. (Apud Cury, p.10)

O decreto $n^{\circ} 86.816$ ampliou as funções da CAPES concedendo a ela mais autonomia e poderes no tocante à elaboração e ao estabelecimento da política de pós-graduação, bem como à coordenação, ao acompanhamento e avaliação dos programas em nível nacional. Sua estrutura básica é mantida, desde essa época, até os dias atuais, na qual a avaliação se constitui em sua espinha dorsal, compondo um de seus setores denominado Diretoria de Avaliação. 
Outro instrumento importante foi o II PNPG (1982/85), que estabeleceu as premissas da política nacional de pós-graduação sob a coordenação da CAPES. O plano, à época, iria identificar a persistência de problemas estruturais que dificultavam o processo de institucionalização e consolidação da pós-graduação, dentre eles: a excessiva dependência de recursos extra-orçamentários; a sujeição a repentinos cortes de verba; a instabilidade empregatícia e profissional de docentes, técnicos e pessoal de apoio; a inexistência de um número satisfatório de professores (lideranças) em condições de atender a todos os programas existentes e a expansão de novos cursos. Segundo Barros (1998, p.137),

Na tentativa de ir ao encontro dos problemas que afetam o desempenho do sistema de pós-graduação, o plano estabelece como objetivos básicos:

1- aumentar qualitativamente o desempenho global do sistema, pela criação de estímulos e condições favoráveis, bem como acionando mecanismos de acompanhamento e avaliação;

2- compatibilizar pós-graduação e pesquisa com prioridades nacionais e com a natureza das matérias de formação básica que a precederam na universidade;

3- buscar uma melhor coordenação entre as diversas instâncias governamentais que atuam na área da pós-graduação.

Esse é um momento muito importante, pois, com base nesses novos instrumentos, firma-se a crença, ao longo dos anos 1980, de que só por meio da coordenação das diversas instâncias da pós-graduação, com maior centralização da CAPES, e do acompanhamento e do aperfeiçoamento do sistema de avaliação, que seria possível a expansão acadêmico-científica da pós-graduação no país com a criação de novos cursos e a consolidação de centros de qualidade.

Na década de 1980, sugiram no âmbito da Geografia mais quatro Programas de Pós-Graduação com o Curso de Mestrado, foram eles: Universidade Estadual de Campinas — UNICAMP (1983); Universidade Federal de Santa Catarina — UFSC (1985); Universidade Federal de Sergipe — UFSE (1985); Universidade Federal de Minas Gerais — UFMG (1988); Universidade Estadual Paulista — Campus Presidente Prudente — UNESP/PP (1988); e um Programa apenas com o Curso de Doutorado, o segundo no país depois da USP (1971), que foi a Universidade Estadual Paulista - Rio Claro - UNESP/RC (1983). No final dos anos 1980, tínhamos na área de Geografia no país 9 Cursos de Mestrado e 3 de Doutorado, tendo dobrado o número de cursos da década anterior, com uma visível concentração geográfica na Região Sudeste. Apenas os Programas de Pós-Graduação em Geografia da UFPE, da UFSE e da UFSC se situavam em outras regiões fora do Sudeste.

Se a década de 1960 abrigou os primeiros passos na implantação de um sistema nacional de pósgraduação, tendo como parâmetro o parecer CFE n 977/65, e a década de 1970 foi marcada por iniciativas de institucionalização e fortalecimento da CAPES a frente do PNPG, associado aos Planos Nacionais de Desenvolvimento (PNDs), os anos 1980 se caracterizaram pelo esforço de implantação do sistema de avaliação e mecanismos de acompanhamento dos programas, buscando unificar nacionalmente a pósgraduação e orientar o seu crescimento com o estabelecimentos de diretrizes, metas e prazos a serem cumpridos pelos programas. Os cursos de pós-graduação em geografia, mestrado e doutorado, foram fortemente marcados por este momento. Até então, os prazos de realização e defesas de dissertações e teses eram bastante elásticos, havendo descompasso entre os diferentes programas e turmas. Foi a partir desta década que a CAPES passou, efetivamente, a tomar para si a tarefa de coordenação dos diferentes programas nas diversas áreas do conhecimento e regiões do país.

Na década seguinte, nos anos 1990, após um ataque de dissolução sofrido pela CAPES no Governo Collor (Cury, 2005, p.10), essas iniciativas e ações se desdobrariam, sobretudo a partir de 1995, na busca 
de um aperfeiçoamento do sistema de avaliação e acompanhamento, com o estabelecimento de parâmetros nacionais, comuns a todos os programas, o sistema qualis e a classificação por meio de conceitos. Esse "aperfeiçoamento" do sistema de avaliação acabou por gerar, necessariamente, pela forma como se realizou, uma acentuada competição entre os programas de pós-graduação, na qual o dado quantitativo tende a se sobrepor ao qualitativo, e tensionar, em muitos níveis e graus, as relações: entre os diferentes programas de uma mesma área; entre estes e a CAPES; entre os colegas e pesquisadores dos diferentes programas; e, finalmente, entre as diferentes áreas do conhecimento entre si, num jogo, mais político do que acadêmico, por posições, colocando o debate sobre o produtivismo na ordem do dia.

\section{A ANPEGE NO CONTEXTO DA PÓS-GRADUAÇÃO EM GEOGRAFIA}

Quando a Associação Nacional de Pós-Graduação e Pesquisa em Geografia (ANPEGE) foi criada em 1993, as bases da pós-graduação brasileira já estavam postas e consolidadas e o atual sistema de avaliação delineado. Desde modo, se o surgimento da ANPEGE se deu tardiamente em relação a outras associações do gênero, que nasceram ainda nos anos 1970 (ANPEC, ANPOCS, ANPED), o mesmo não podemos dizer em relação à política e institucionalização da pós-graduação no Brasil. A ANPEGE nasce exatamente no momento em que a CAPES já consolidada, como órgão regulador da pós-graduação e como importante agência de fomento, associando o ensino e a pesquisa, terá condições de promover uma grande expansão dos cursos de pós-graduação no país, na qual a área de Geografia naturalmente se inclui.

Ao mesmo tempo, a criação da ANPEGE garantiu a afirmação da pós-graduação em geografia no Brasil, até então muito dispersa como campo político e área de interesses específicos. A entidade, assim, identificou e abriu novos canais para o aprimoramento da ciência geográfica, ampliando o espaço de debates dos principais problemas atinentes á pós-graduação. Não deve ser negligenciada a capacidade da entidade em realizar trabalho de sistematização da produção geográfica no país, sobretudo, tratando-se de um país caracterizado pela imensa diversidade de paisagens e complexa trama de relações sociais, o Brasil exige e exigia múltiplas possibilidades de leituras e interpretações.

Desde sua criação, a ANPEGE tem propiciado um trabalho de aprofundamento do conhecimento da produção científica em geografia no país. Destaca-se a rápida expansão dos cursos de pós-graduação, a partir de meados dos anos 1990, e, mais recentemente, denota-se um processo de descentralização desses cursos que se instalam em estados do Nordeste, Norte e Centro-Oeste (Quadro 1).

A produção científica brasileira na área de geografia, vem impor à ANPEGE uma postura aguerrida no sentido de orientar e dar suporte aos programas na busca novas fontes de financiamento, aperfeiçoando o processo de acesso democrático à obtenção de dados e informações, bem como permitir a ampliação do leque de pesquisadores e a melhoria de suas formações.

Atualmente, depois de pouco mais de uma década de percalços, desde a sua fundação, a ANPEGE tem desfrutado do reconhecimento de sua importância na congregação dos programas e discussão de problemas pertinentes. As experiências adquiridas na discussão da problemática da pós-graduação em geografia no Brasil permitiram uma rápida avaliação da importância desse papel histórico da entidade ao liderar ações afirmativas nesse campo do conhecimento. 
Quadro 1 - Brasil: Programas de Pós-Graduação em Geografia (1996, 2001, 2004, 2007 e 2008)

\begin{tabular}{|c|c|c|c|c|c|c|}
\hline REGIÄO & UNIVERSIDADE & 1996 & 2001 & 004 & 007,008 & Fiveis \\
\hline \multirow{3}{*}{ NORTE } & UFAM (AM) & & & & & $M$ \\
\hline & UNIR (RO) & & & & & $M$ \\
\hline & UFPA (PA) & & & & & $M$ \\
\hline \multirow{7}{*}{ NORDESTE } & UFC (CE) & & & & & $\mathrm{MD}$ \\
\hline & UFPB (PB) & & & & & $M$ \\
\hline & UECE (CE) & & & & & $M$ \\
\hline & UFRN (RIN) & & & & & $M$ \\
\hline & UFPE (PE) & & & & & $M D$ \\
\hline & UFSE (SE) & & & & & $M D$ \\
\hline & UFBA (BA) & & & & & $M$ \\
\hline \multirow{12}{*}{ SUDESTE } & PUC - RJ (RJ) & & & & & $M$ \\
\hline & $\mathrm{PUC} / \mathrm{SP}$ (SP) & & & & & $M$ \\
\hline & UFES (ES) & & & & & $M$ \\
\hline & UNICAMP (SP) & & & & & $M D$ \\
\hline & UFF (RJ) & & & & & $M D$ \\
\hline & UERJ (RJ) & & & & & $M$ \\
\hline & UFU (MG) & & & & & $M D$ \\
\hline & PUC/MG (MG) & & & & & MD \\
\hline & UFMG (MG) & & & & & $M D$ \\
\hline & UFRJ (RJ) & & & & & $M D$ \\
\hline & USP/GH (SP) & & & & & $M D$ \\
\hline & USP/GF (SP) & & & & & $M D$ \\
\hline
\end{tabular}

Fonte: CAPES (1996, 2001, 2004, 2007, 2008)

Organizado Por: SILVA, J. B. da; DANTAS, E. W. C. 
Quadro 1 - Brasil: Programas de Pós-Graduação em Geografia (1996, 2001, 2004, 2007 e 2008) (continuação)

\begin{tabular}{|c|c|c|c|c|c|c|c|}
\hline & UNESP/PP (SP) & & & & & & $M D$ \\
\hline & UNESP /RC (SP) & & & & & & $M D$ \\
\hline \multirow{7}{*}{$\begin{array}{l}\text { CENTRO- } \\
\text { OESTE }\end{array}$} & UFGD (MS) & & & & & & $M$ \\
\hline & UFMT (MT) & & & & & & $M$ \\
\hline & UFMS (MS) & & & & & & $M$ \\
\hline & UFMS (Três Lagoas) & & & & & & $M$ \\
\hline & UNB (DF) & & & & & & $M$ \\
\hline & UFG (GO) & & & & & & $M D$ \\
\hline & UFG(Itajaí) & & & & & & $M$ \\
\hline \multirow{10}{*}{ SUL } & UFPG (PR) & & & & & & $M$ \\
\hline & UNIOESTE (PR) & & & & & & $M$ \\
\hline & FURG (RS) & & & & & & $M$ \\
\hline & UFSM (RS) & & & & & & $M D$ \\
\hline & UFRGS (RS) & & & & & & $M D$ \\
\hline & UFPR (PR) & & & & & & M \\
\hline & UEL (PR) & & & & & & $M$ \\
\hline & UEM (PR) & & & & & & $M D$ \\
\hline & UFSC (SC) & & & & & & $M$ \\
\hline & UNICENTRO(PR) & & & & & & $M$ \\
\hline BRASIL & & 11 & 22 & 29 & 38 & 41 & \\
\hline
\end{tabular}

Fonte: CAPES (1996, 2001, 2004, 2007, 2008)

Organizado Por: SILVA, J. B. da; DANTAS, E. W. C. 
Ao nosso ver, a ANPEGE alcança, hoje, sua maturidade num momento em que a Pós-Graduação em Geografia no Brasil se consolida, como área de produção científica e conhecimento em toda a sua diversidade. Nesse sentido, além da criação de novos cursos, cabe salientar a ampliação de linhas de pesquisas capazes de atrair o interesse de jovens pesquisadores, bem como o paulatino aperfeiçoamento de professores.

Apesar de sua recente trajetória no seio da comunidade de geógrafos, as origens da ANPEGE remontam a mais de duas décadas, quando profissionais ligados aos cinco primeiros Programas de Pós-Graduação em Geografia, criados a partir de 1971 sentiram necessidade em dar corpo às reivindicações dos recém criados cursos de pós-graduação.

Reuniram-se, assim, em 1983, os Programas das seguintes universidades: USP — Geografia Física e Geografia Humana - UNESP (Rio Claro), UFRJ e UFPE, quando criaram as bases do que viria a ser a ANPEGE. Tratava-se do I Encontro Nacional de Pós-Graduação em Geografia18, marco no processo de discussão e de analise da situação da Pós-Graduação em Geografia no Brasil. Esse I Encontro resultou em grande parte de iniciativas de professores da USP. Nele se instituiu o que seriam as bases para futuras discussões que culminaram na proposta de discussão específica sobre a situação da pós-graduação em geografia no país, quando da realização do 4o. Congresso Brasileiro de Geógrafos, na cidade de São Paulo, em julho de 1984, promovido pela AGB. A discussão da pós-graduação em geografia, no interior desse evento, organizadas em forma de Mesas Redondas (3) e Sessões de Debates (3), permitiu o encontro e a troca de experiências entre professores e pós-graduandos de vários Cursos e Universidades, além da proposição de ações concretas que, anos mais tarde, conduziam à criação da ANPEGE.

O Rio de Janeiro foi sede do II Encontro realizado na UFRJ, em 1986, e coube a Rio Claro, através da UNESP, a organização do III Encontro, realizado em 1987.

Embora todos esses encontros tenham sido preliminares, estes foram importantíssimos para a criação da ANPEGE, como entidade capaz de catalisar os interesses da pós-graduação em geografia no país. A criação da ANPEGE vai acontecer, de fato, no IV Encontro Nacional de Pós-Graduação em Geografia, realizado na UFSC, Florianópolis, entre 1 e 4 de setembro de 1993. A ANPEGE - Associação Nacional de Pós-Graduação e Pesquisa em Geografia, data do dia 4 (quatro de setembro de 1993), tendo os representantes dos Programas existentes à época, assinado a ata de criação e aprovado o primeiro estatuto da mesma.

Data também dessa reunião, a eleição da primeira diretoria da entidade, assim constituída:

- Prof. Dr. Milton de Almeida Santos(USP) - Presidente

- Profa. Dra. Maria Adélia Aparecida de Souza(USP) - Secretária

- Profa. Dra. Amalia Inés Geraiges de Lemos(USP) - Tesoureira

Durante a gestão do Professor Milton Santos, foi realizado o famoso e concorrido I Encontro Internacional da ANPEGE, sobre o tema: "Lugar, Formação Sócio-Espacial, Mundo", entre 8 e 10 de setembro de 1994, na USP. Esse evento marcou com muita expressão a capacidade de fazer da ANPEGE. Essa primeira diretoria ainda organizou o $\mathrm{I}^{\circ}$ Encontro Nacional da ANPEGE, entre 5 e 9 de setembro de 1995, na cidade de Aracaju. O tema do evento, "Território Brasileiro e Globalização", foi abordado em formas de mesas-redondas, reuniões de trabalho, comunicações e Assembléia Deliberativa. Deste Encontro e da $1^{\text {a }}$. Assembléia Deliberativa participaram 23 representantes dos 9 Programas associados. Nela, depois de tratados vários temas, a nova diretoria foi eleita, constituída por professores da UFRJ. 
Passada quase uma década e meia, a abrangência atual da ANPEGE impõe a necessidade de abrir novos canais de comunicação capazes de provocar uma interação e possibilidade de intercâmbio entre os diferentes programas e cursos, considerando a articulação política da produção científica em geografia. Nesse sentido alguns novos desafios estão postos.

\section{E A ANPEGE CONTINUA... ALGUMAS QUESTÕES}

A geografia firma-se cada vez mais como escola autônoma, ou melhor, escolas autônomas. A extensão e diversidade de paisagens do país permitem múltiplas leituras. O IBGE, os Departamentos de Geografia, a AGB - Associação dos Geógrafos Brasileiros e, por fim, a ANPEGE criaram ambientes propícios para que essa ou essas escolas se desenvolvessem. O contato com membros de escolas nacionais no país ou no exterior foi fundamental para o aprimoramento da geografia brasileira. Hoje fazemos nossa leitura do Brasil. A geografia e suas diversas matizes, herdadas das escolas francesa, alemã e americana, contribuiu com as ciências humanas, tornando-se um saber indispensável para a compreensão do Brasil contemporâneo.

O contexto político brasileiro favorece, ao nosso ver, no momento, a discussão sobre o fomento de pesquisa científica, especialmente no campo da geografia. Espera-se que a ANPEGE, chancele e auspicie um encontro maior entre os agentes produtores do conhecimento geográfico e propicie, através de linhas de divulgação, uma grande difusão da produção geográfica brasileira. Esta postura não deve ser restrita ao ambientes de pós-graduação. Muito pelo contrário. Espera-se uma grande interação entre os departamentos e coordenações dos cursos de bacharelado e de licenciatura, as coordenações dos cursos de pós-graduação lato e stricto sensu. Ao reunir pessoas para refletir sobre as alternativas de políticas públicas voltadas à produção científica em geografia, estará a ANPEGE prestando um grande serviço à ciência brasileira.

Assim, este comprometimento exigirá de professores e alunos condições de análise da realidade nacional, compreensão dos condicionamentos ideológicos e percepção das reais vinculações da Universidade com a sociedade global. E como a praxis nunca se dá em plano individual há a necessidade de se apoiar e fomentar as organizações das categorias profissionais. Para Paulo Freire, "a praxis verdadeira que consiste num processo de libertação e na busca de transformação do mundo, exigirá que o professor, através da consciência tome distância da cotidianidade em que geralmente se acha imerso e permita a emersão da realidade e o seu conseqüente desvelamento" (Freire 1978) ${ }^{19}$.

Desse modo, gostaríamos de deixar aqui, a título de contribuição, algumas questões, de cunho mais político, para o debate:

- tendo em vista o atual contexto da pós-graduação brasileira, dominada por uma perpersctiva que tende a valorizar mais os aspectos quantitativos (numéricos) da formação e da produção em detrimento dos qualitativos, acarretando no chamado "produtivismo", que tipo de contribuição pode dar a ANPEGE para essa discussão?

- considerando que cada programa de pós-graduação em geografia mantém sua vinculação com a administração superior de suas instituições e os respectivos órgãos de fomento, quais seriam os limites e as competências de uma instituição como a ANPEGE?

- levando-se em conta o expressivo número de cursos de graduação em geografia no país, deveria ser maior a demanda pela pós-graduação específica. Entretanto, tem aumentado o coro dos que falam do chamado "fracasso da formação", insistindo na discussão da precariedade dos cursos de graduação. Alunos desmotivados, sem interesse, concluem o curso com aproveitamento medíocre, interrompendo aí

Revista da ANPEGE. v. 5, 2009 
seu processo de formação. A partir do exposto, qual seria o papel da ANPEGE no processo de melhoria da qualidade da graduação?

- pensar "fracassos da formação" pressupõe apreender de que forma o geógrafo se insere no mercado de trabalho. Existe a possibilidade da ANPEGE discutir uma questão corporativa, considerando que ela é aberta ao ingresso de profissionais provenientes de várias áreas do conhecimento?

AANPEGE, enquanto entidade máxima da pós-graduação em geografia, apesar de sua história recente firma compromisso e, certamente, ampliará sua contribuição na formação de profissionais competentes e conscientes do seu papel e na melhoria da qualidade da produção científico-acadêmica em geografia. Pensamos que este deva ser o caminho e a direção da entidade.

\section{NOTAS}

(1) De acordo com Octavio Ianni (1979), o período que se inicia em 1930 e se estende até 1945, término da Segunda Grande Guerra, em que o Estado assume um caráter nitidamente intervencionista, pode ser considerado como marco nas transformações estruturais ocorridas na base do sistema capitalista que "revelam o contexto histórico e estrutural em que o Estado brasileiro se encontrava. Em particular, demonstram as possibilidades e condições de expansão do modo capitalista de produção, em um país dependente. Nota-se, contudo, que as perspectivas dessa expansão tornaram-se reais precisamente numa época de crise do sistema global; isto é, de rupturas estruturais em nível nacional e internacional" (p.24).

(2) Antecedendo a USP, criada em 25 de janeiro de 1934, tivemos: em 17 de janeiro de 1909, a iniciativa pioneira da Escola Universitária Livre de Manáos, que depois passou a ser conhecida como Universidade de Manáos, esta foi desintegrada após a queda do Ciclo da Borracha em cursos superiores isolados, e refundada em 1962, pela Lei Federal 4.069, com o nome de Universidade do Amazonas; em 19 de dezembro de 1912, a fundação da Universidade do Paraná - Curitiba; em 7 de setembro de 1920, a criação da Universidade do Rio de Janeiro, que serviu de modelo para a organização da Universidade de Minas Gerais, fundada em 7 de setembro de 1927. Posteriormente, a Universidade do Rio de Janeiro seria reestruturada e denominada de Universidade do Brasil (1937). (Barros, 1998, p. 57) (3) Além desses dois geógrafos franceses, estiveram na origem do primeiro curso universitário de Geografia do Brasil os cientistas sociais franceses: De Martonne, Fernand Bradel e Jean Bastide, entre outros. Fonte: http://www. geografia.fflch.usp.br/posgraduacao/apresentacao.htm, acessado em 13/06/2009.

(4) O Instituto Brasileiro de Geografia e Estatística (IBGE), foi fundado em 1937, numa incorporação ao Instituto Nacional de Estatística (INE), criado em 1934. Desde então, o IBGE tem como objetivo articular e coordenar as pesquisas estatísticas, unificando a ação dos serviços especializados em funcionamento no País, assim como produzir e sistematizar informações sobre o território nacional, contar a população, mostrar como a economia evolui através do trabalho e da produção das pessoas, revelando ainda como elas vivem. Fonte: http://www.ibge.gov.br/ home/disseminacao/eventos/missao/instituicao.shtm, acesso em 12/06/2009.

(5) Cf. Ata de Fundação, http://www.agb.org.br/nacional/ler-noticias/ata-de-fundacao/, acesso em 12/06/2009.

(6) A Criação da CAPES foi efetivada por meio do decreto $n^{\circ} 29.741$, de 11/06/1951, assinado pelo Presidente Getúlio Vargas e o Ministro da Educação e Saúde Simões Filho, publicado no Diário Oficial de 13/07/1951 (Apud Cury, 2005). Na década de 1950 era muito comum o mecanismo de criação de órgãos públicos sob a forma de Campanha na tentativa de solucionar problemas que dificultavam o desenvolvimento de determinadas áreas (Barros, 1998, p.83).

(7) Cf. Decreto no 29.741, de 11/06/1951. 
(8) Cf. História e Missão, http://www.capes.gov.br/sobre-a-capes/historia-e-missao, acessado em 12/06/2009.

(9) Idem.

(10) Cf. Decretos 53.932, de 26/05/1964; 54.356, de 30/09/1964 e 59.707, de 12/12/1966.

(11) A FINEP foi criada em 1967, para institucionalizar o Fundo de Financiamento de Estudos de Projetos e Programas, constituído em 1965. Em 1974 a FINEP substituiu e ampliou o papel até então exercido pelo Banco Nacional de Desenvolvimento Econômico e Social (BNDES) e seu Fundo de Desenvolvimento Técnico-Científico (FUNTEC), constituído em 1964 com a finalidade de financiar a implantação de programas de pós-graduação nas universidades brasileiras. Fonte: http://www.finep.gov.br/o_que_e_a_finep/a_empresa.asp?codSessaoOqueeFINEP=2 (12) O Parecer do CFE no 977/65 apoia-se no Artigo 69 da Lei nº 4.024, de 20/12/1961 (LDB - Lei de Diretrizes e Bases), que estabelece as atribuições do ensino superior, e na Lei ${ }^{\circ}$ 4.888.A/65, do Estatuto do Magistério (Cury, 2005, p.11).

(13) Cf. História e Missão, http://www.capes.gov.br/sobre-a-capes/historia-e-missao, acessado em 12/06/2009.

(14) Os cursos de pós-graduação na USP, no formato que existem hoje, iniciaram-se em 1969, quando o MEC promoveu a criação oficial dos cursos de pós-graduação no Brasil. Entretanto, a formação de doutores pela Universidade de São Paulo é anterior à iniciativa do governo federal. A primeira tese de doutorado em Geografia foi defendida em 1944. Fonte: http://www.geografia.fflch.usp.br/posgraduacao/apresentacao.htm, acessado em 13/06/2009.

(15) Cf. História e Missão, http://www.capes.gov.br/sobre-a-capes/historia-e-missao, acessado em 12/06/2009.

(16) Cf. Decreto 74.299, de 18/07/1974.

(17) Publicado no Diário Oficial de 06/01/1982.

(18) Anais do I Encontro Nacional de Pós-Graduação em Geografia, São Paulo, FAPESP/CNPq, 1984

(19) FREIRE, Paulo. "Pedagogia do oprimido", Rio, Paz e Terra, 1978

\section{REFERÊNCIAS BIBLIOGRÁFICAS}

BARros, E. M. C. Política de Pós-Graduação: um estudo da participação da comunidade científica. São Carlos: EdUFSCar, 1998.

BEIGUELMAN, B. Reflexões sobre a pós-graduação brasileira. In: PALATNIK, Marcos (org.) Pós-graduação no Brasil. Rio de Janeiro: EdUFRJ, 1997. p. 33-47

CARVALHO, J. M. A formação do professor pesquisador em nível superior no Brasil: análise histórica do discurso do governo e da comunidade acadêmico-científica. Tese de doutorado. Faculdade de educação da Universidade do Rio de Janeiro, 1992.

CÓRDOVA, R. et alii. A pós-graduação na América Latina: o caso brasileiro. Brasília: UNESCO/CRESALC MEC/SESU/CAPES, 1986.

CURY, C. R. J. “Quadragésimo ano do parecer CFE nº 977/65”. Revista Brasileira de Educação, ANPED, n. 30, p.7-20, set/dez - 2005 .

IANNI, Octavio. Estado e Planejamento Econômico no Brasil (1930-1970). $3^{\mathrm{a}}$ ed. Rio de Janeiro: Civilização Brasileira, 1979.

SOUZA PAUlA, M. C. et alii. Política de Formação de Recursos Humanos para a Pesquisa: o caso do Brasil. Brasília, CNPq, 1988.

Sites

Revista da ANPEGE. v. 5, 2009 
http:/www.agb.org.br/nacional/ler-noticias/ata-de-fundacao/

http://www.capes.gov.br/sobre-a-capes/historia-e-missao

http://www.finep.gov.br/o_que_e_a_finep/a_empresa.asp?codSessaoOqueeFINEP=2

http://www.geografia.fflch.usp.br/posgraduacao/apresentacao.htm

http://www.ibge.gov.br/home/disseminacao/eventos/missao/instituicao.shtm

Recebido em abril de 2009

Aceito em agosto de 2009 